oceanic water comes to within a mile or two of shore and the island lies close to the convergence of the North and South Equatorial currents.

\section{Tropical Research Laboratory}

Operating now in its second year is the McGill University Tropical Research Laboratory, located at Waterford, Barbados. The laboratory, which is administered through the departments of Geography and Meteorology of McGill University, has undertaken, in its initial stage, investigations into climatology and agricultural meteorology in the Caribbean and plans later to expand into a meteorological station as well as a graduate centre in the tropics for geographical research.

Among its immediate activities is the measurement of potential and latent evaporation at a tropical station. These results, with the usual meteorological data, will be published at regular intervals each year for the information of interested research workers in the field of climatology. Results of these investigations will also be used locally in experiments planned to aid the Department of Agriculture in the expansion of irrigation and land-use schemes.

\title{
PEST INFESTATION RESEARCH, 1958
}

$\mathrm{T}$ HE report of the Pest Infestation Research Board of the Department of Scientific and Industrial Research for $1958^{*}$ reflects the increased concern with problems of food storage and handling in overseas territories and on board ships, and with the problems that may arise when grain is stored for very long periods under different conditions of temperature and of oxygen concentration. Two longterm experiments have been set going, in which the effect of low temperature $\left(4.5 \pm 0.5{ }^{\circ} \mathrm{C}\right.$.) and low oxygen concentration (between 1 and 2 per cent), singly or in combination, on the keeping quality of dry wheat, will be investigated. A hard Canadian and a soft English wheat are being used. Chemical analyses, milling tests and bread-making tests were made initially and will be repeated at intervals over a period of ten or twelve years. Since it is quite inexpensive to maintain large stores of grain in these conditions the outcome of this investigation will be of considerable practical importance.

Films of insecticidal lacquers containing dieldrin and endrin have proved very effective in killing adult flour beetles (Tribolium confusum). It has now been shown that flour up to at least $2 \mathrm{in}$. deep becomes toxic to the beetles after being in contact with the lacquer for two weeks and retains this toxicity for many months. Until the amount of contamination that might occur in practice has been established, caution in the use of these particular insecticidal

* Department of Seientific and Industrial Research. Pest Infestation Research : The Report of the Pest Infestation Research Boar with the Report of the Director of Pest Infestation Research. Pp.
$\mathrm{v}+55+8$ plates. (London : H.M. Stationery Office, 1959.) 5s. net. preparations is advocated. Whereas much is known about the susceptibility to insecticides of the insects of stored products, very little is known about the mites. An investigation of the flour mite (Acarus siro) is now being undertaken to make good this deficiency.

The use of gas-proof sheets for covering produce during fumigation has been increasing greatly in recent years. But users have been unable to obtain guidance on the selection of the material best suited to this purpose. Some have proved unsuitable because of lack of durability of the coating, others are highly permeable to methyl bromide and yet others become stiff after contact with liquid methyl bromide. A systematic study has now been carried out in co-operation with manufacturers, and the Laboratory should soon be in a position to put forward agreed specifications.

In addition to these problems of immediate practical importance the Laboratory has continued to produce a large amount of basic information on the insects and other organisms affecting stored products. This has consisted in detailed life-history studies in controlled physical environments, the systematics of insect pests, the response of insects to fumigants and other insecticides. In the Biochemistry Section work of even wider interest has been carried out. The physiological and toxicological studies on the mode of action of insecticides and the biochemical nature of acquired resistance to insecticides being carried out in that section is fundamental to applied entomology of every kind.

\section{X-RAY MEASUREMENT OF THERMAL EXPANSION PERPENDICULAR TO THE LAYER PLANES OF ARTIFICIAL AND NATURAL GRAPHITES}

\author{
By E. G. STEWARD and B. P. COOK \\ Research Laboratories, The General Electric Co., Ltd., Wembley
}

\begin{abstract}
THERE are apparently conflicting data in the literature concerning X-ray diffraction measurements of $(a)$ the thermal expansion of graphitic carbons and $(b)$ the possible variation of the expansion coefficient with the proportion $(p)$ of disordered (turbostratic) stacking of the layer planes.

For natural (Ceylon) graphite ( $p$ almost zero) over the range $15-800^{\circ} \mathrm{C}$., the variation of the interlayer spacing $d$ (A.) with temperature $t$ (deg. C.) is given by Nelson and Riley ${ }^{1}$ as $d=3.3525+90.54 \times 10^{-6} t$
\end{abstract}

$+6 \cdot 33 \times 10^{-9} t^{2}$ (giving an average expansion coefficient ( $\alpha$ ) defined as $\frac{d_{2}-d_{1}}{d_{1} \Delta t}$, of $28.5 \pm 0 \cdot 1^{\circ} \mathrm{C}^{-1}$ ) and by Máuyama as $d=3 \cdot 3535+82 \cdot 41 \times 10^{-6} t+10 \cdot 30 \times 10^{-9}$ $t^{2}\left(\alpha=27 \cdot 0 \pm c .0 \cdot 1^{\circ} \mathrm{C}^{-1}\right)$ (Fig. 1). If in either determination the experimental errors have been so under-estimated that the difference in the resulting values of the average expansion coefficient is not in fact significant, then the inclusion in the appropriaie 